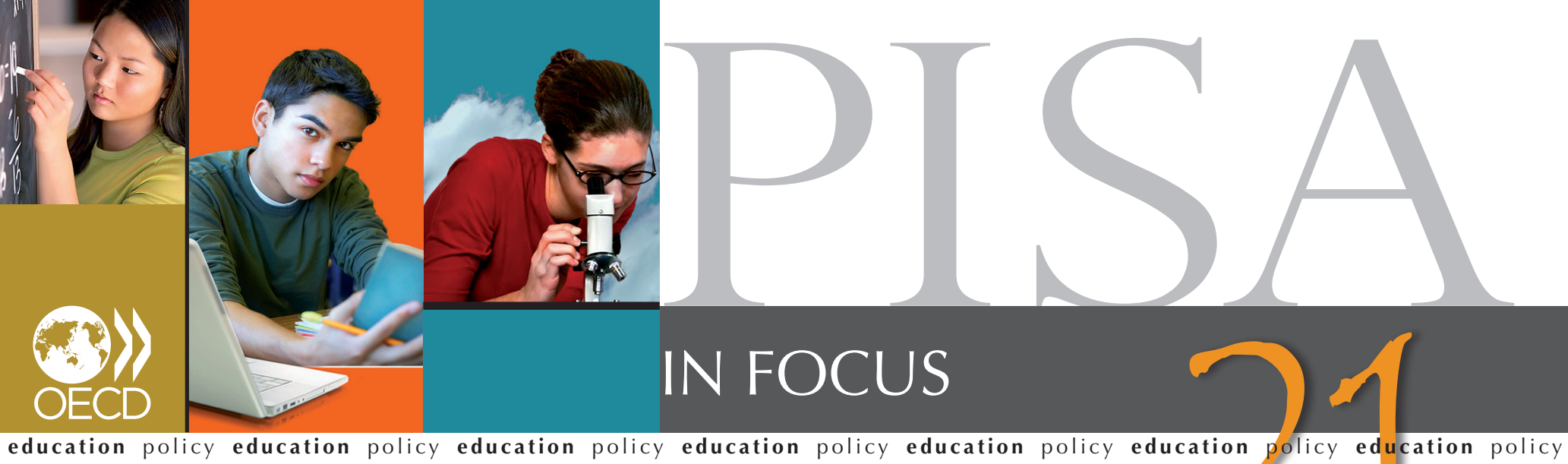

\title{
Do today's 15-year-olds feel environmentally responsible?
}

- Most 15-year-olds in OECD countries have some understanding of environmental issues and feel that threats to the environment are a serious concern for them and/or for other people in their country.

- Scientific understanding of the environment is key if students are to have a realistic appreciation of environmental challenges facing humanity. Students without sufficient knowledge of science consistently underestimate the time needed to find solutions to such environmental problems as what to do with nuclear waste or how to stop the loss of plant and animal species.

Knowledge and scientific understanding of the environment can help to instill a sense of responsibility towards the environment. But if young people cannot make the link between what they learn in school and the environmental challenges that surround them in real life, or if they have unrealistically high or low expectations of meeting those challenges, then they might not be able to fully capitalise on their academic training in these topics. Education - and parents - can help students to make those connections and develop realistic attitudes towards solutions.

Understanding and a sense of responsibility go hand in hand.
The PISA 2006 survey tested students on their scientific understanding of environmental issues and asked them - and, in some countries, their parents - about their attitudes towards environmental issues. Students were asked whether they were familiar with the issues of air pollution, energy shortages, extinction of plant and animal species, clearing of forests for other land use, water shortages, and nuclear waste. In addition, students and parents were asked whether they believed that those issues represent a serious concern for themselves or others in their country, and how optimistic they were that solutions would be found to improve the situation over the next 20 years.

The vast majority of 15-year-old students reported they know or have learned something about environmental issues. On average across OECD countries, fewer than $3 \%$ of students reported that they are not sure what "air pollution" or "extinction of plants and animals" is; only around 5\% reported not being sure what "water shortages" and "clearing of forests for other land use" is; fewer than 10\% weren't sure what "energy shortages" were; and $11 \%$ were not sure what was meant by "nuclear waste".

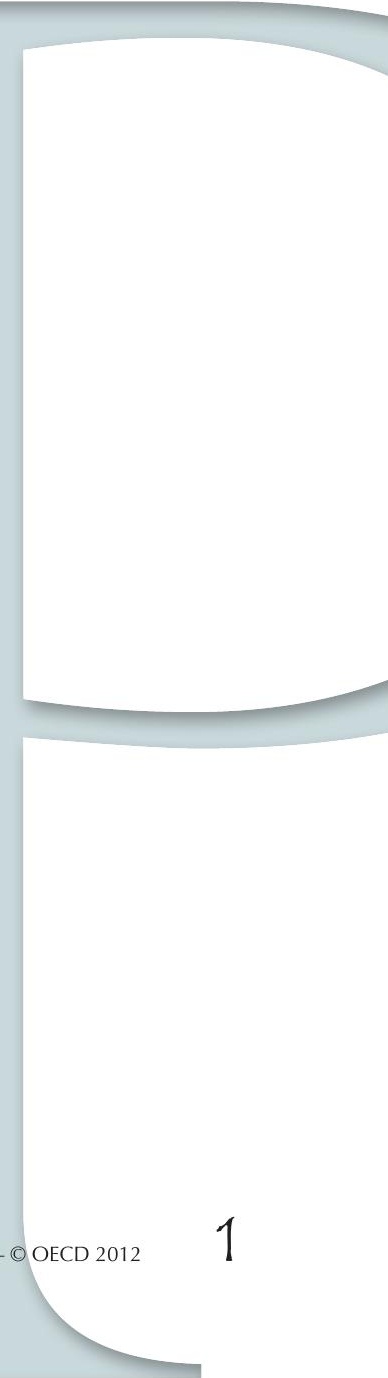


Learning in school influences attitudes outside of school

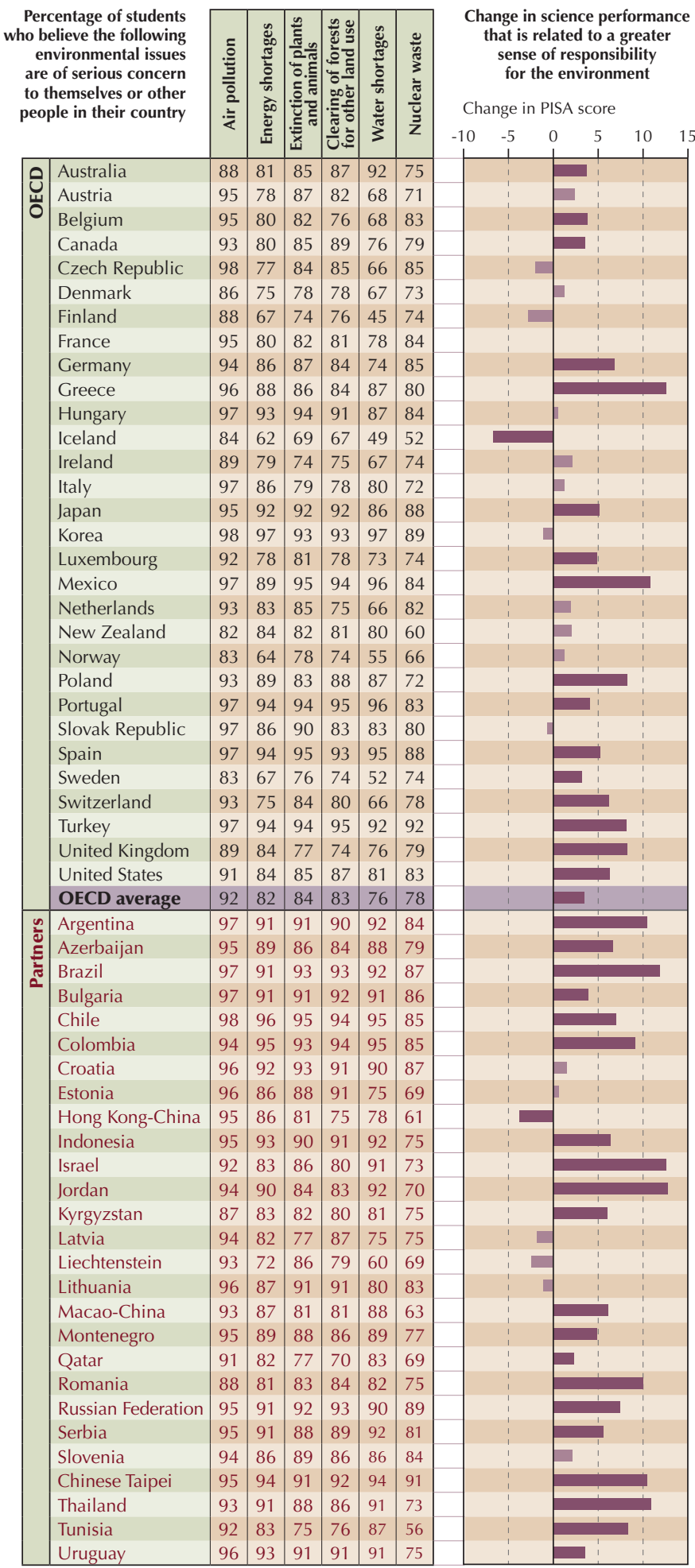

Note: Changes in science performance that are statistically significant are indicated in a dark tone. The change in science performance shows the change in the score on the PISA science test that is associated with a one-unit change in the index of students' responsibility for environmental issues, ffter accounting for students' and schools 'background.

15-Year-Olds Perform in Environmental Science and Geoscience in PISA 2006, Table A3.14.

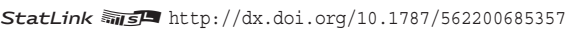

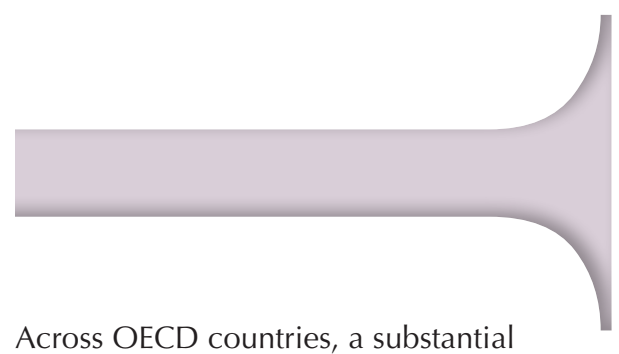

Across OECD countries, a substantial proportion of students reported feeling a strong sense of personal and social responsibility towards these environmental issues - i.e. they reported that environmental issues are a serious concern for themselves and/or for other people in their country. For example, on average across OECD countries, $92 \%$ of students believe that air pollution represents a serious concern for themselves or others in their country, and over $80 \%$ of students feel the same about energy shortages, the extinction of plants and animals, and the clearing of forests. Some $78 \%$ and $76 \%$ of students, respectively, feel the same about water shortages and nuclear waste.

\section{But optimism about the future of} the environment is in short supply...

Students are not optimistic that the threats to the environment will be significantly reduced over the next 20 years.

For example, on average across OECD countries, only $15 \%$ or fewer of students believe that there will be improvements with respect to nuclear waste, the extinction of plants and animals, and the clearing of forests for other land use; $16 \%$ of students feel the same about air pollution, only $18 \%$ are optimistic about tackling water shortages, and $21 \%$ feel the same about energy shortages.

Schools appear to play a central role as a source of knowledge about environmental issues. Fifteen-year-olds who participated in PISA reported that they mainly learn about the environment at school. On average across OECD countries, $58 \%$ of students reported that schools are their main source of information on nuclear waste issues, and 59\% reported the same with respect to water shortage issues. 


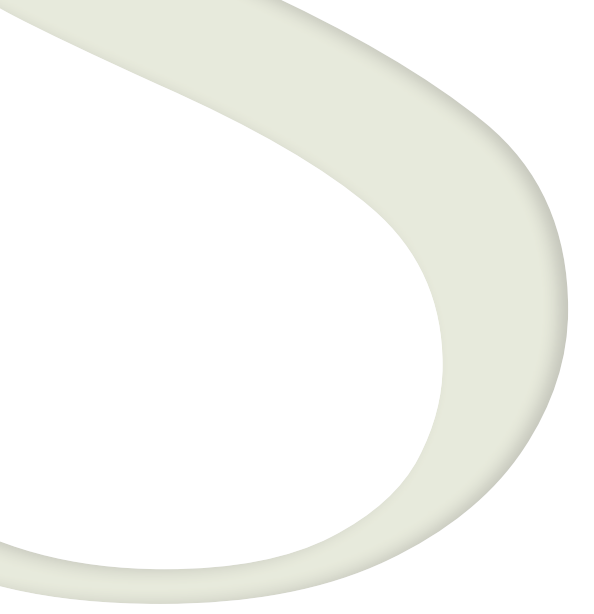

Around $60 \%$ of students reported that schools are their main source of information about energy shortages; $65 \%$ reported that schools are their main source of information on clearing of forests for other land use; $70 \%$ reported the same for the issue of extinction of plants and animals; and $76 \%$ reported that schools are their main source of information on air pollution.

While students acquire knowledge about the environment at school, families also play a key role in forming students' attitudes and opinions about environmental issues, which, in turn, can shape students' willingness to adopt environmentally responsible behaviours later on. Students often share their parents' sense of responsibility and optimism towards the environment, although the strength of this correlation varies across countries and is stronger when it comes to feelings of optimism than with a sense of personal responsibility. Students and their parents in Turkey and the partner country Colombia, for example, responded similarly to the question of whether environmental conditions will improve over the next two decades, while a similarity between students and their parents in response to this question was less evident in Denmark, Germany, Iceland, Korea, Luxembourg and New Zealand. Students and parents in Turkey and the partner country Colombia also tended to agree that most of these environmental issues are of serious concern to themselves and/or to others in their country; in Denmark, Iceland and Luxembourg, students and their parents often had different responses to this statement.

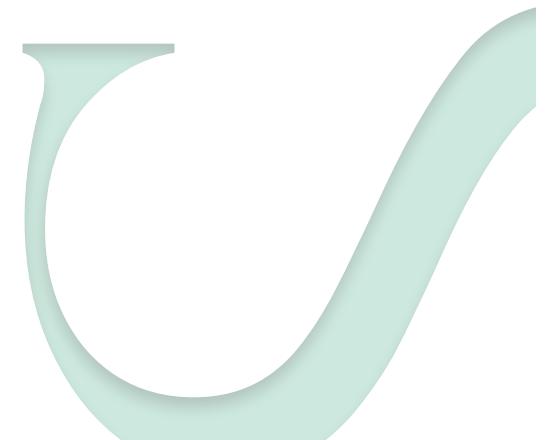

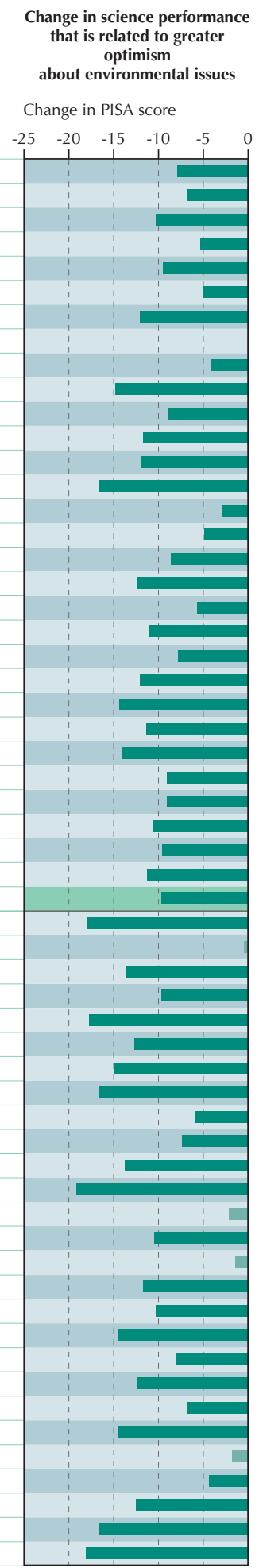

Note: Changes in science performance that are statistically significant are indicated in a dark tone. The change in science performance shows the change in the score on the PISA science test that is associated with a one-unit change in the index of students' optimism about environmental issues, 'fter accounting for students' and schools' background.

-Olds Perform in Environmental Science and Geoscience in PISA 2006, Table A3.14.

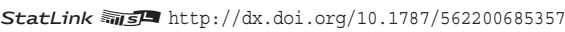


....and is often associated with poorer performance in environmental science.

PISA 2006 also found that there was no strong association between students' performance in environmental science and their sense of responsibility towards the environment when comparing students from similar backgrounds who attend similar schools. However, the extent to which students feel optimistic that solutions to environmental problems will be found over the next 20 years was negatively related to student performance in environmental science: the lower their scores in environmental science, the more optimistic students were that the situation will improve over the next two decades. This may be due to the fact that students who lack a deep understanding about environmental issues may be more optimistic, or that students who are optimistic about the future of the environment have less incentive to become more knowledgeable about environmental science.

Students largely share their parents' sense of responsibility towards the environment and their optimism about solving environmental problems

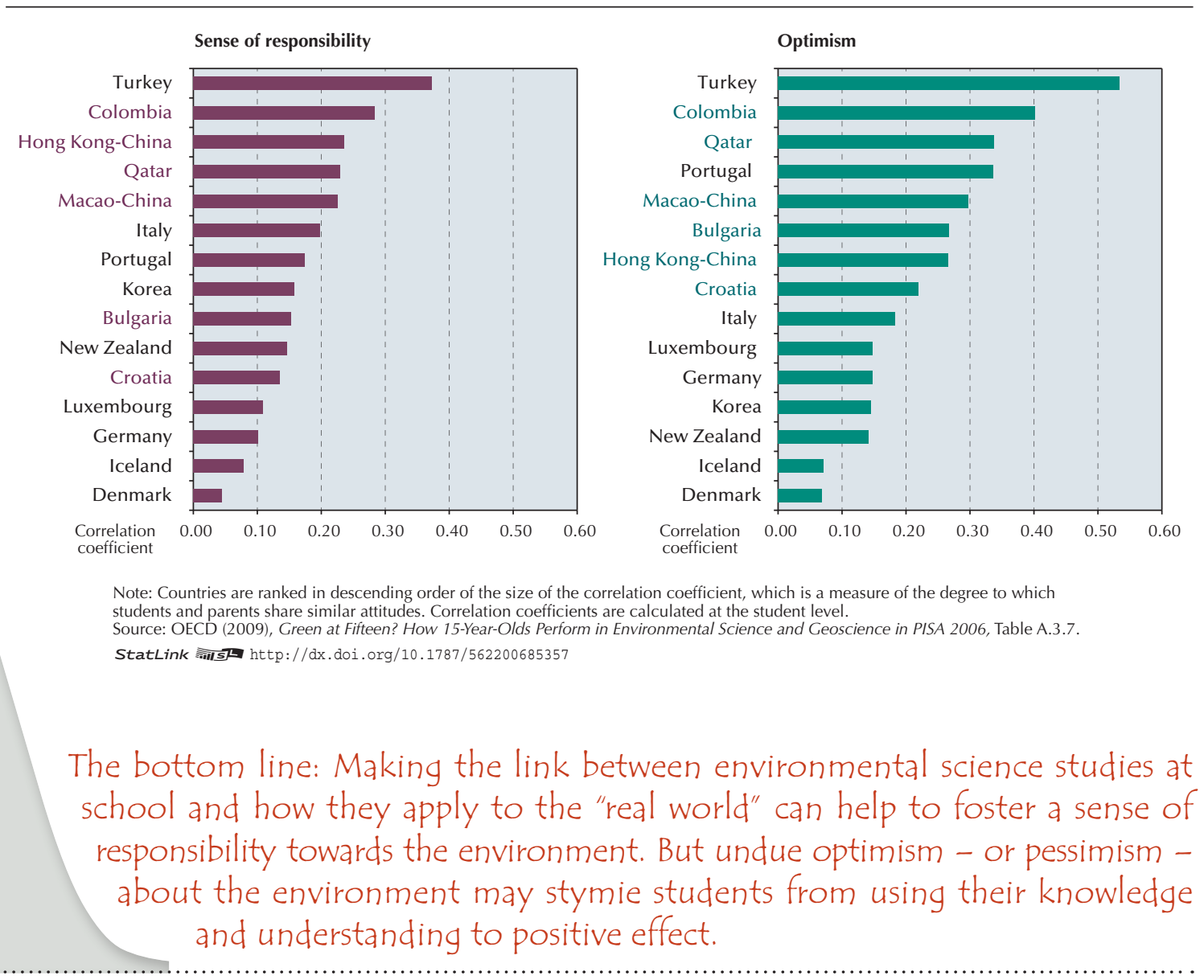

For more information

Contact Francesca.Borgonovi (Francesca.Borgonovi@oecd.org)

See Green at Fifteen? How 15-year-olds Perform in Environmental Science and Geoscience in PISA 2006, OECD Publishing.

Visit

www.pisa.oecd.org www.oecd.org/pisa/infocus
Coming next month

How do immigrant students fare in disadvantaged schools? 